\title{
Anti-inflammatory effect of baicalin in rats with adjuvant arthritis and its autophagy- related mechanism
}

\author{
Xi Chen ${ }^{\mathrm{a}}$, Yingying Wang ${ }^{\mathrm{a}}$, Jiye Cai ${ }^{\mathrm{b}}$, Shuang Wang ${ }^{\mathrm{a}}$, Zihao Cheng ${ }^{\mathrm{c}}$, Zhengxu Zhang ${ }^{\mathrm{c}}$ and \\ Chengyi Zhang ${ }^{\mathrm{c}, *}$ \\ ${ }^{a}$ College of Basic Medicine, Beihua University, Jilin, China \\ ${ }^{\mathrm{b}}$ Mingzheng Forensic Identificaiton Centre of Jilin, Jilin, China \\ ${ }^{\mathrm{c}}$ College of Pharmacy, Beihua University, Jilin, China
}

\begin{abstract}
.
BACKGROUND: It has been found that baicalin have anti-inflammatory effects since it reduces the elevated levels of proinflammatory cytokines. Meanwhile, it has also been shown that baicalin brings positive effects against rheumatoid arthritis (RA). However, little is observed on its beneficial effects on adjuvant arthritis.

OBJECTIVE: To consider the anti-inflammatory influence of baicalin on adjuvant arthritis rats and its related autophagy mechanism

METHODS: In this research, there are six groups of rats, each has 10 rats in it. These groups are normal group (normal saline), model group (normal saline), dexamethasone group $(0.125 \mathrm{mg} / \mathrm{kg}$ dexamethasone), low-dose baicalin group (50 $\mathrm{mg} / \mathrm{kg}$ baicalin), medium-dose baicalin group (100 mg/kg baicalin) and high-dose baicalin group ( $200 \mathrm{mg} / \mathrm{kg}$ baicalin). The degrees of adjuvant-induced swelling in rats' feet were measured every 4 days and the arthritis scores were calculated every 7 days. The inflamed joint tissues were taken after rats were sacrificed. The rat' joints showed pathological changes, which were observed by HE staining. The relative expression levels of inflammatory factors IL-6, IL-1, IL-17, TNF- $\alpha$, COX2, and COX1 in the rats' snovial tissues were detected by RT-PCR. As for the expression levels of autophagy markers Beclin1, Atg5, Atg7, Atg12, microtubule-associated protein-light chain3-II (LC3-II), Bcl-2, and Bax in the synovial tissue, they were discoverd by Western blot.

RESULTS: Baicalin could significantly inhibit the inflammatory response of adjuvant arthritis rats.

CONCLUSIONS: RT-PCR studies showed that the different doses of baicalin could inhibit the expression of TNF-a, IL-6, IL-1, IL-17, COX2 and COX1 in the synovial tissue $(P<0.05$ or $P<0.01)$. Western blot studies showed that the different doses of baicalin could reduce the expression of Atg5, Atg7, Atg12, LC3-II, Beclin1 and Bcl-2 proteins, and increase the expression of Bax proteins in the synovial tissue.
\end{abstract}

Keywords: Baicalin, rheumatoid arthritis, synovial fibroblasts, autophagy

\section{Introduction}

Rheumatoid arthritis (RA) is an autoimmune disease often accompanied by synovitis and joint destruction [1], which is characterized by the continuous proliferation of fibroblast-like synovial cells (FLSs),

\footnotetext{
${ }^{*}$ Corresponding author: Chengyi Zhang, College of Pharmacy, Beihua University, Jilin 132013, China. E-mail: zchyjl@ 163. com.
}

0928-7329 (c) 2022 - The authors. Published by IOS Press. This is an Open Access article distributed under the terms of the Creative Commons Attribution-NonCommercial License (CC BY-NC 4.0). 


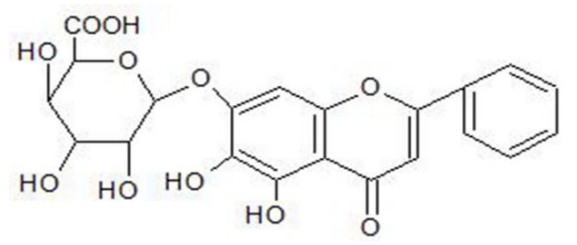

Fig. 1. Chemical structure of baicalin.

inflammatory cell infiltration and joint destruction [2], this will cause the gradual destruction of bones and cartilage [3]. At present, 5 to 50 per 100,000 people suffer from the disease in developed countries every year [4]. Various drugs are now used as treatment for RA in clinic, but most of them have serious adverse reactions after long-term use [5].

Baicalin, a kind of flavonoids (Fig. 1), is mainly separated from the dried root of Scutellariae Radix, and it has been reported that the leaves of Cerasus tomentosa (Thunb) contain baicalin. Studies have shown that the compounds baicalein and baicalin in scutellaria can be used as drugs for the treatment of autoimmune diseases, including rheumatoid arthritis and inflammatory bowel disease [6]. Wall (Cerasus tomentosa) contains baicalin $[7,8]$ with antioxidant, anti-inflammatory and anti-tumor effects $[9,10]$. Bai et al. [11] confirmed that baicalin could lead to a reduction in the expression of NF- $\kappa \mathrm{B}$ protein in the synovial fibroblasts as well as synovial tissue, and alleviate the inflammation of joints in the collagen-induced arthritis of rats. Baicalin has an obvious positive effect in improving the swelling of ankle and inhibit the differentiation of Th17 cells in vivo in rats arthritis model [12]. The synovial tissue in RA has a high level of autophagy that can stimulate the secretion of inflammatory cytokines, proliferation of synovial cells and anti-apoptosis [13]. Meanwhile, the increase of autophagy in synovial tissue has shown a correlationship that is positive with the severity of RA disease [14]. Kim et al. [15] found that inhibiting the autophagy of cells could increase the apoptosis of cells. Therefore, autophagy may be regarded as a potential possibility for the treatment of RA.

In this research, baicalin was used to treat rats which have adjuvant arthritis, then the expression of autophagy-related factors. The changes in inflammatory factors and the levels of apoptosis-related factors were investigated for the purpose of exploring the anti-inflammatory effect and the autophagy-related mechanism of baicalin in rats with adjuvant arthritis.

\section{Method}

\subsection{Experimental animals and materials}

\subsubsection{Experimental animals}

Sixty male Wistar rats, aged from 6 to 7 weeks and weighing $200 \pm 20$ g, were purchased from Changchun Yisi Laboratory Animal Technology Co., Ltd., China), and raised under specific pathogenfree (SPF) conditions, and at constant temperature $\left(24^{\circ} \mathrm{C}\right)$ and $45 \%-55 \%$ relative humidity in our laboratory. After the experiment, each rat was injected intraperitoneally with $25 \%$ urethane and sacrificed by anesthesia.

\subsubsection{Experimental materials}

Baicalin (baicalin extract with 95\% purity, No. Rf20090814, Xi' an Reifen Bioengineering Co., Ltd., China); Dexamethasone Tablets (No. 151101, Guangdong South China Pharmaceutical Group Co., Ltd., 
China). Freund's complete adjuvant (FCA, No. 76J00110, Beijing Dingguo Changsheng Biotechnology Co., Ltd., China; Antibodies for $\beta$-actin (ab8227), LC3-II (ab48394), Beclin1(ab62557), HRP-conjugated seondary antibodies (ab205718) were purchased from Abcam (Cambridge, UK). Antibodies for Bcl-2 (A16776), Bax (A15646), Atg5 (A0203), Atg7 (A0691), Atg12 (A17045) were purchased from AB clonal (Wuhan, China); ECL substrate chemiluminescent solution (E411-03, Vazyme, China); GAPDH, IL-6, IL-1, TNF-, COX1 and COX2 primers (Beijing Dingguo Changsheng Company, China); reverse transcription cDNA kit and high pure total RNA rapid extraction kit (BioTake, USA).

\subsection{Establishment of adjuvant arthritis model in rats, grouping and administration}

Wistar rats are established after one week of adaptive feeding, 10 male Wistar rats are assigned to each group, and there are 60 rats in total. As for groups, there are normal group (CON), model group (MOD), dexamethasone group ( $0.25 \mathrm{mg} / \mathrm{kg}$ dexamethasone) (DXMS), low-dose baicalin group $(50 \mathrm{mg} / \mathrm{kg}$ baicalin), medium-dose baicalin group (100 mg/kg baicalin) and baicalin high-dose group $(200 \mathrm{mg} / \mathrm{kg}$ baicalin), 10 rats in each group. Normal rats were excluded, those in the other group were subcutaneously injected with $0.2 \mathrm{~mL}$ Freund's complete adjuvant on their right hind plantar to induce the inflammation for 12 days. After the establishment of adjuvant arthritis model in rats, rats in the different baicalin and dexamethasone groups were intragastrically given the corresponding agents once daily, and an equal volume of saline were given to the normal group and model control group rats in the same way, successively for 28 days, during which all the rats were carefully observed.

\subsection{Observation indicators}

Swelling degree: During the experiment, the volume of the right hind plantar was measured every 4 days and the degree of toe swelling was calculated.

$$
\text { Foot swelling }(m l)=V t-V o
$$

Where $V o$ and $V t$ stand for some point of view the plantar of volume before and after inflammation, separately.

Arthritis index: After the establishment of arthritis model, the pathological changes of rat foot joints were examined daily. The macroscopical signs of arthritis were qualitatively scored every 7 days since the first signs of arthritis were found. The scoring criteria were the same as the one in the Journal of Experimental Medicine [16]. 0 point: normal ankle joint; 1 point: swelling of small toe joint; 2 points: swelling of both toe joint and plantar; 3 points: swelling below ankle joint; 4 points: all swelling including ankle joint. 4 Points was the highest score for one foot, and 16 was that for one rat, and the arthritis score of each rat's four feet was calculated as arthritis index [16].

Histopathological evaluation: The rats were sacrificed and their right hind ankle joints were taken. The right posterior ankle joint was fixed with $10 \%$ neutral formaldehyde, $10 \%$ EDTA was decalcified, and the decalcification solution was replaced every 4 days. After decalcification, the ankle joint was dehydrated for 24 hours. The joints were paraffin-embedded, sliced continuously at 5 micron thick and the slices were stained with HE. Observe the pathological changes of rats' joints under an optical microscope.

\subsection{Detection of IL-17, IL-6, TNF- $\alpha, I L-1, C O X-2$ and COX-1 mRNA by RT-PC}

In order to extract the total mRNA of the synovial tissue, a RNA extraction kit was used in the experiment. Otal RNA was used as the template for the reverse transcription of cDNA under the conditions 
Table 1

RT-PCR primer sequences

\begin{tabular}{|c|c|c|}
\hline Primer name & Primer sequence (5'-3') & Fragment length/bp \\
\hline \multirow[t]{2}{*}{ GAPDH } & Forward primer: GGCAAGTTCAACGGCACAG & 124 \\
\hline & Reverse primer: GCCAGTAGACTCCACGACAT & \\
\hline \multirow[t]{2}{*}{ TNF- $\alpha$} & Forward primer: ATGTGGAACTGGCAGAGGAG & 127 \\
\hline & Reverse primer: AGTAGACAGAAGAGCGTGGTG & \\
\hline \multirow[t]{2}{*}{ IL-1 $\beta$} & Forward primer: GGATGATGACCTGCTAGT & 148 \\
\hline & Reverse primer: CACTTGTTGGCTTATGTTCTGTC & \\
\hline \multirow[t]{2}{*}{ IL-6 } & Forward primer: CCAАCTТCCAАTGCТСТССТААТ & 125 \\
\hline & Reverse primer: CGAGTAGACCTCATAGTGACCTT & \\
\hline \multirow[t]{2}{*}{ IL-17 } & Forward primer: CGCCGAGGCCAATAACTTTC & 104 \\
\hline & Reverse primer: GGTTGAGGTAGTCTGAGGGC & \\
\hline \multirow[t]{2}{*}{$\mathrm{COX} 2$} & Forward primer: CCCGCCCCATCTAACATCTC & 234 \\
\hline & Reverse primer: CCCCACATGGAGGAATAGGC & \\
\hline \multirow[t]{2}{*}{ COX1 } & Forward primer: GCCAGTATTAGCAGCAGGTATC & 121 \\
\hline & Reverse primer: GCCGAAGAATCAGAATAGGTGTT & \\
\hline
\end{tabular}

proposed by the instructions of reverse transcription cDNA kit $\left(42^{\circ} \mathrm{C}\right.$ for $50 \mathrm{~min}$ and $72^{\circ} \mathrm{C}$ for $\left.10 \mathrm{~min}\right)$. RT-PCR reaction system $(25 \mu \mathrm{l}): 12.5 \mu \mathrm{l}$ of $2 \times$ Taq Master mix, $9.5 \mu \mathrm{l}$ double distilled water, $1 \mu \mathrm{l}$ upstream primer, $1 \mu \mathrm{L}$ downstream primer and $1 \mu \mathrm{L}$ cDNA. The reversely transcripted cDNA functioned as the template for the PCR amplification, the reaction conditions used were as follow: pre-denaturation at $94^{\circ} \mathrm{C}$ for $3 \mathrm{~min}$, followed by 20 cycles of denaturation at $94^{\circ} \mathrm{C}$ for $30 \mathrm{~s}$ and annealing at $65^{\circ} \mathrm{C}$ for $30 \mathrm{~s}$ and extension at $72^{\circ} \mathrm{C}$ for $1 \mathrm{~min}$, fully extended at $72^{\circ} \mathrm{C}$ for $10 \mathrm{~min}$. After the completion of PCR procedures, the electrophoresis of the samples was performed at $100 \mathrm{~V}$ for $40 \mathrm{~min}$ (see Table 1 for the sequences of PCR primers). Then the semi-quantitative analysis of the target gene mRNA was carried out, and the data were analyzed according to the absorbance ratio of the target gene band to the GAPDH band. The above experiments were reduplicated at least three times.

\subsection{Western blot analysis}

Cell lysis buffer, Phenylmethanesulfonyl fluoride (PMSF) and phosphatase inhibitor were used to extract the total protein from the synovial tissue. BCA protein concentration determination kit was used to quantitatively analyze the extracted proteins. Specific procedures: preparation of concentrated glue and separation gel (12\% SDS-polyacrylamide gel; loading $50 \mu \mathrm{g}$ protein, electrophoresis ( $80 \mathrm{~V}$ for $30 \mathrm{~min}$, $100 \mathrm{~V}$ for $15 \mathrm{~h}$ ); transmembrane (PVDF membrane, $100 \mathrm{~V}$ for $1 \mathrm{~h}$ ); blocking: 5\% skim milk powder at room temperature for $1 \mathrm{~h}$; incubation with the primary antibodies at $4^{\circ} \mathrm{C}$ overnight: diluted rabbit anti-rat antibodies with TBST, Bcl-2, Bax, Atg5, Atg7, Atg12, LC3-II, Beclin1 and $\beta$-actin; recovery of the primary antibodies, washing the membranes three times with TBST, 10 min each time; incubation with the second antibodies HRP-labeled goat anti-rabbit $\operatorname{IgG}(1: 10000$ dilution) at room temperature for $1 \mathrm{~h}$; washing the membranes with TBST three times, $10 \mathrm{~min}$ each time; Immunoassay with enhanced chemiluminescent substrate kit, and $\beta$-actin was used as a protein loading control. Use Image $\mathbf{J}$ software to quantify the density of specific bands. The above experiments were reduplicatd at least three times.

\subsection{Statistical analysis}

Graphpad Prism5 software was used for the statistical analysis. The swelling degree of rat's plantar and arthritis index were expressed as mean $\pm \mathrm{s}$, and one-way ANOVA was used to compare samples between groups. $P<0.05$ was considered meaningful in statistics. 
Table 2

Effect of baicalin on the plantar swelling in rats (mean $\pm \mathrm{s}, n=10, \mathrm{ml}$ )

\begin{tabular}{|c|c|c|c|c|c|c|c|}
\hline Groups & $4 d$ & $8 \mathrm{~d}$ & $12 d$ & $16 \mathrm{~d}$ & $20 d$ & $24 d$ & $28 \mathrm{~d}$ \\
\hline Normal & $\begin{array}{l}0.05 \pm \\
0.07\end{array}$ & $\begin{array}{l}0.06 \pm \\
0.06\end{array}$ & $\begin{array}{l}0.07 \pm \\
0.04\end{array}$ & $\begin{array}{l}0.11 \pm \\
0.08\end{array}$ & $\begin{array}{l}0.07 \pm \\
0.05\end{array}$ & $\begin{array}{l}0.05 \pm \\
0.09\end{array}$ & $\begin{array}{l}0.02 \pm \\
0.05\end{array}$ \\
\hline Model & $\begin{array}{l}0.82 \pm \\
0.08^{\# \#}\end{array}$ & $\begin{array}{l}0.81 \pm \\
0.05^{\# \#}\end{array}$ & $\begin{array}{l}0.81 \pm \\
0.09^{\# \#}\end{array}$ & $\begin{array}{l}0.81 \pm \\
0.07^{\# \#}\end{array}$ & $\begin{array}{l}0.80 \pm \\
0.06^{\# \#}\end{array}$ & $\begin{array}{l}0.83 \pm \\
0.09^{\# \#}\end{array}$ & $\begin{array}{l}0.84 \pm \\
0.07^{\# \#}\end{array}$ \\
\hline Dexamethosone & $\begin{array}{l}0.74 \pm \\
0.09\end{array}$ & $\begin{array}{l}0.61 \pm \\
0.04^{* *}\end{array}$ & $\begin{array}{l}0.49 \pm \\
0.08^{* *}\end{array}$ & $\begin{array}{l}0.36 \pm \\
0.07^{* *}\end{array}$ & $\begin{array}{l}0.25 \pm \\
0.07^{* *}\end{array}$ & $\begin{array}{l}0.15 \pm \\
0.05^{* *}\end{array}$ & $\begin{array}{l}0.06 \pm \\
0.05^{* *}\end{array}$ \\
\hline Low-dose baicalin & $\begin{array}{l}0.81 \pm \\
0.07\end{array}$ & $\begin{array}{l}0.82 \pm \\
0.03\end{array}$ & $\begin{array}{l}0.79 \pm \\
0.04\end{array}$ & $\begin{array}{l}0.78 \pm \\
0.04\end{array}$ & $\begin{array}{l}0.71 \pm \\
0.11^{*}\end{array}$ & $\begin{array}{l}0.66 \pm \\
0.09^{* *}\end{array}$ & $\begin{array}{l}0.62 \pm \\
0.09^{* *}\end{array}$ \\
\hline Medium-dose baicalin & $\begin{array}{l}0.81 \pm \\
0.06\end{array}$ & $\begin{array}{l}0.78 \pm \\
0.04\end{array}$ & $\begin{array}{l}0.70 \pm \\
0.11^{*}\end{array}$ & $\begin{array}{l}0.62 \pm \\
0.08^{* *}\end{array}$ & $\begin{array}{l}0.54 \pm \\
0.08^{* *}\end{array}$ & $\begin{array}{l}0.52 \pm \\
0.08^{* *}\end{array}$ & $\begin{array}{l}0.43 \pm \\
0.09^{* *}\end{array}$ \\
\hline High-dose baicalin & $\begin{array}{l}0.77 \pm \\
0.08\end{array}$ & $\begin{array}{l}0.69 \pm \\
0.08^{* *}\end{array}$ & $\begin{array}{l}0.60 \pm \\
0.04^{* *}\end{array}$ & $\begin{array}{l}0.53 \pm \\
0.09^{* *}\end{array}$ & $\begin{array}{l}0.45 \pm \\
0.07^{* *}\end{array}$ & $\begin{array}{l}0.42 \pm \\
0.10^{* *}\end{array}$ & $\begin{array}{l}0.37 \pm \\
0.07^{* *}\end{array}$ \\
\hline
\end{tabular}

\section{Results}

\subsection{Effect of baicalin on the toe swelling of rats}

After completing the intradermal injection process of Freund's adjuvant into the rats' right hind plantar, the acute local inflammation of the plantar was observed during the first 4 days, followed by a series of secondary inflammations such as the swelling of the side and forelimb plantar, nodules on the tail and red spots on the ear. Compared with that in the normal group, the joint swelling degree of the rats' joints in the model group at different time points $(4,8,12,16,20,24$ and 28 days) was significantly different $(P<$ 0.01 ), suggesting that the establishment of rat adjuvant arthritis model was successful; compared with that in the model group, the toe swelling degree of adjuvant arthritis rats in baicalin-treated groups was significantly reduced $(P<0.05$ or $P<0.01)$, in which the reduced swelling degree was more significant in high-dose baicalin group at 20 days after the administration $(P<0.01)$; on the 12th day after the administration, compared with that in the model group, the toe swelling degree of rats in dexamethasone group was significantly reduced $(P<0.01)$ and that in baicalin-treated groups was significantly reduced on the same day as well $(P<0.05$ or $P<0.01)$, and the effect on the degree of reduction in the joint swelling in the baicalin-treated groups was less than that in dexamethasone group (Table 2).

\subsection{Effect of baicalin on the arthritis index in adjuvant arthritis rats}

Comparing with the arthritis index of rats in the normal group, that in the model group witnessed a significant increase on the 14th, 21st and 28th day after the administration of Freund's complete adjuvant $(P<0.01)$; and meanwhile the arthritis index of rats in the baicalin-treated groups witnessed a significant decrease on the 21st and 28th day after the administration of Freund's complete adjuvant in a dose-dependent manner $(P<0.01)$, of which the arthritis index in the high-dose baicalin group was most significantly decreased $(P<0.01)$, indicating that baicalin could improve the inflammatory symptoms of adjuvant arthritis rats in varying degrees (Table 3 ).

\subsection{Observation of pathological changes of ankle joint by HE staining}

The HE staining results showed that the structure of ankle joint, the lining of cartilage, the space of joint and the morphology of bone tissue of rats were normal, and no inflammatory cell infiltration in the synovium of rats in the normal group; in the model group, the joint tissue of was significantly abnormal, 
Table 3

Effect of baicalin on the arthritis index in adjuvant arthritis rats (mean $\pm \mathrm{s}, n=10$ )

\begin{tabular}{lllll}
\hline \multirow{2}{*}{ Groups } & \multicolumn{4}{c}{ Arthritis indexes } \\
\cline { 2 - 5 } & \multicolumn{1}{c}{$7 \mathrm{~d}$} & \multicolumn{1}{c}{$14 \mathrm{~d}$} & \multicolumn{1}{c}{$21 \mathrm{~d}$} & $28 \mathrm{~d}$ \\
\hline Normal & \multicolumn{1}{c}{0.00} & 0.00 & 0.00 & 0.00 \\
Model & $6.60 \pm 0.52^{\# \#}$ & $7.10 \pm 0.83^{\# \#}$ & $7.70 \pm 0.67^{\# \#}$ & $7.90 \pm 0.57^{\# \#}$ \\
Dexamethasone & $3.30 \pm 0.67^{* *}$ & $2.70 \pm 0.48^{* *}$ & $1.50 \pm 0.53^{* *}$ & $0.10 \pm 0.03^{* *}$ \\
Low-dose baicalin & $6.40 \pm 0.52$ & $6.60 \pm 0.84$ & $5.80 \pm 0.63^{* *}$ & $5.50 \pm 0.53^{* *}$ \\
Medium-dose baicalin & $6.30 \pm 0.48$ & $5.90 \pm 0.57^{* *}$ & $5.20 \pm 0.42^{* *}$ & $4.90 \pm 0.32^{* *}$ \\
High-dose baicalin & $5.90 \pm 0.74^{*}$ & $4.70 \pm 0.82^{* *}$ & $4.10 \pm 0.57^{* *}$ & $3.50 \pm 0.53^{* *}$ \\
\hline
\end{tabular}

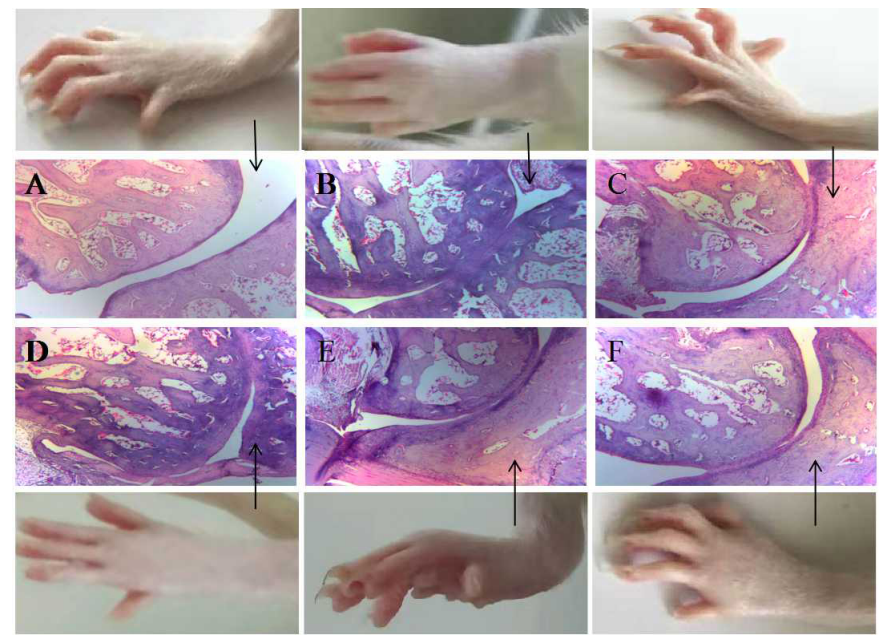

Fig. 2. Effects of baicalin on the ankle joint tissue of rats (40X); A: normal group (the ankle tissue of normal rats); B: model group (the ankle tissue of adjuvant arthritis rats); C: dexamethasone group (the ankle tissue of adjuvant arthritis rats); D-F: $50 \mathrm{mg} / \mathrm{kg}$ baicalin group, $100 \mathrm{mg} / \mathrm{kg}$ baicalin group and $200 \mathrm{mg} / \mathrm{kg}$ baicalin group, respectively (the ankle tissue of adjuvant arthritis rats).

the synovium was significantly proliferated, and the infiltration of inflammatory cells, the vasodilation and the erosion of cartilage as well as bone were found; compared with that in the model group, the chronic inflammation of synovial tissue of adjuvant arthritis rats, characterized by inflammatory cell infiltration, cartilage destructionpannus formation, and bone erosion, was significantly improved in baicalin-treated groups in a dose-dependent manner (Fig. 2).

\subsection{Effects of baicalin on the expression levels of inflammatory factor mRNA in the synovial tissue}

As the Fig. 3 shows, the expression trends of TNF- $\alpha$, IL-1 $\beta$, IL-6, IL-17 and COX 2 mRNA in the synovial tissue of rats were similar in the different groups, and the expression of COX1 in different groups did not change significantly in statistics $(P>0.05)$; comparing with the rats in the normal group, the expression levels of IL-1 $\beta$, IL-6, IL-17, TNF- $\alpha$ and COX2 in the model group was significantly increased $(P<0.01)$; meanwhile the expression levels of TNF- $\alpha$, IL-1 $\beta$, IL-6, IL-17 and COX2 in baicalin-treated groups were remarkably decreased in a dose-dependent manner $(P<0.05$ or $P<0.01)$.

\subsection{Effects of baicalin on the expression levels of autophagy-related and apoptosis-related proteins}

Western blot was used to disclose the expression of Bcl-2, Bax, LC3-II, Beclin1, Atg5, Atg7 and 

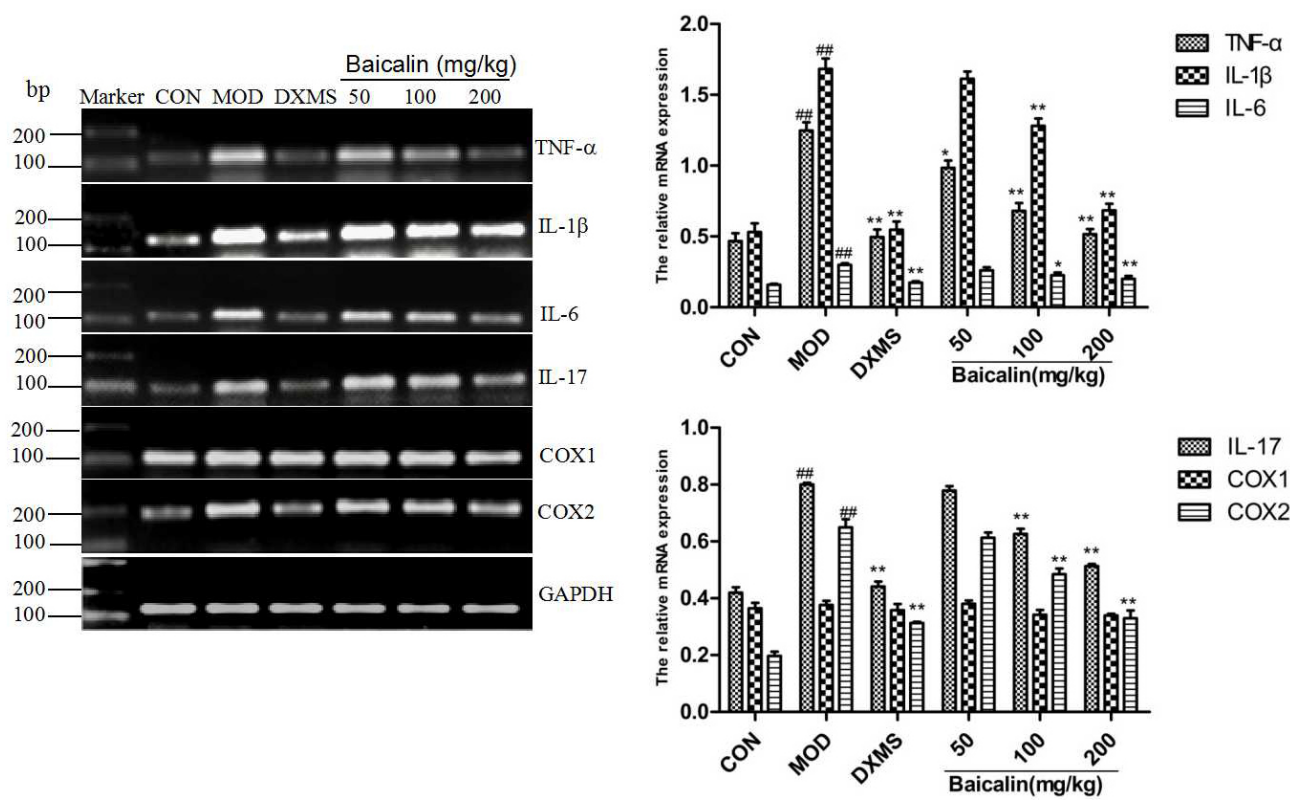

Fig. 3. Effects of baicalin on the expression levels of inflammatory factor mRNA (mean $\pm \mathrm{s}, n=10$ ). CON group: the normal group; MOD group: the model group; DXMS-treated group: the dexamethasone group; baicalin-treated groups: respectively, received baicalin 50,100, and $200 \mathrm{mg} / \mathrm{kg}$. ${ }^{\# \#} P<0.01$, vs the normal group; ${ }^{*} P<0.05,{ }^{* *} P<0.01$, vs the model group.
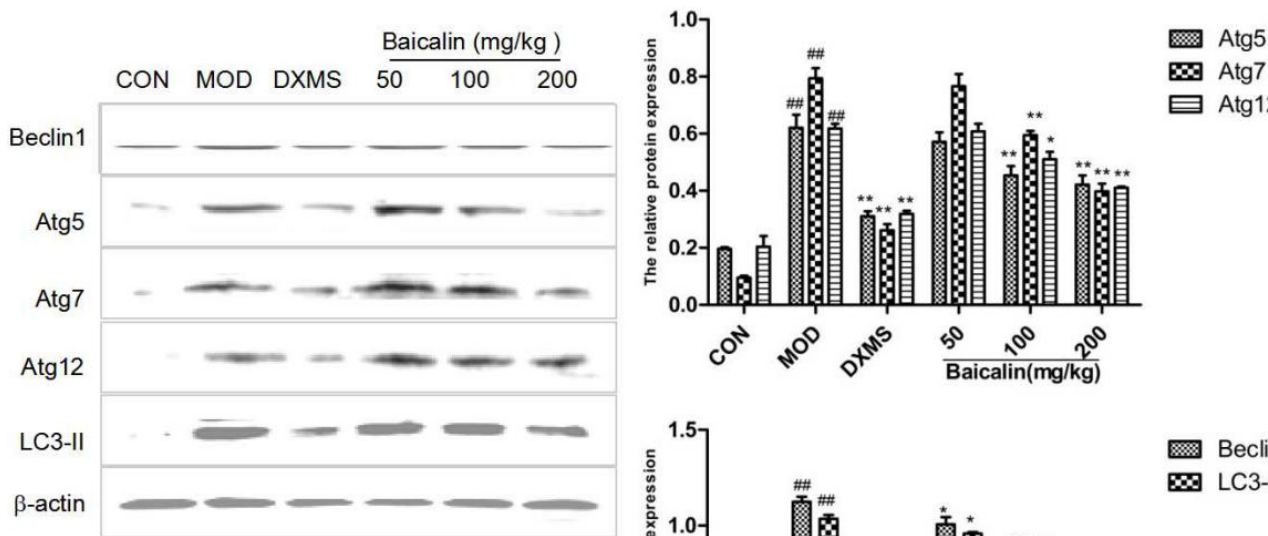

$\operatorname{Atg} 7$

目守12

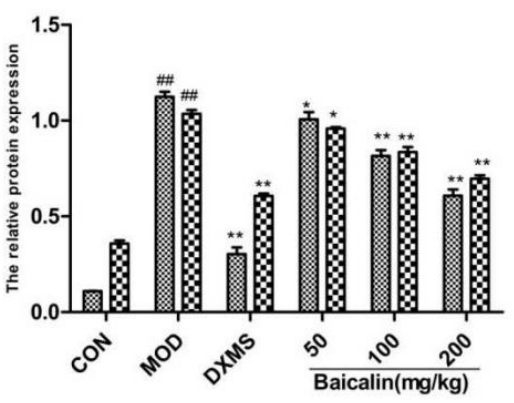

Fig. 4. Effects of baicalin on the expression levels of autophagy-related proteins (mean $\pm \mathrm{s}, n=10$ ). CON group: the normal group; MOD group: the model group; DXMS-treated group: the dexamethasone group; baicalin-treated groups: respectively, received baicalin 50,100, and $200 \mathrm{mg} / \mathrm{kg}$. ${ }^{\#} P<0.05$, ${ }^{\# \#} P<0.01$, vs the normal group; ${ }^{*} P<0.05$, ${ }^{* *} P<0.01$, vs the model group. 

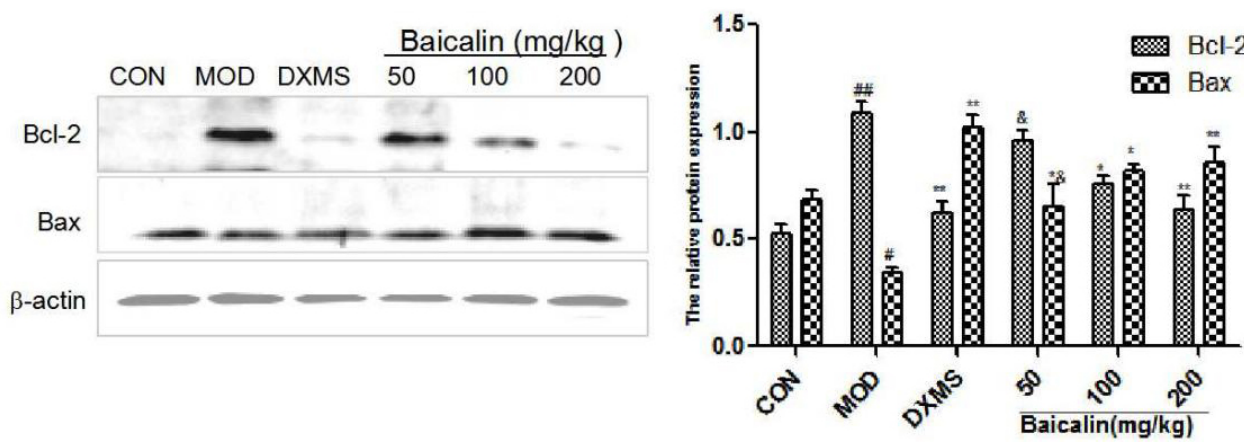

Fig. 5. Effects of baicalin on the expression levels of apoptosis-related proteins (mean $\pm \mathrm{s}, n=10$ ). CON group: the normal group; MOD group: the model group; DXMS-treated group: the dexamethasone group; baicalin-treated groups: respectively, received baicalin 50,100, and $200 \mathrm{mg} / \mathrm{kg}$. \#P<0.05, ${ }^{\#} P<0.01$, vs the normal group; ${ }^{*} P<0.05,{ }^{* *} P<0.01$, vs the model group.

Atg12 proteins in the synovial tissues of rats in the different groups. Compared with those in the normal group, the expression levels of LC3-II, Beclin1, Atg5, Atg7, Atg12 and Bcl-2 proteins in the synovial tissue of rats in the model group were significantly increased, but the expressions of Bax proteins were significantly decreased $(P<0.05$ or $P<0.01)$. In comparison with those in the model group, the expression levels of LC3-II, Beclin1, Atg5, Atg7, Atg12 and Bcl-2 proteins in dexamethasone group were significantly decreased $(P<0.05$ or $P<0.01)$, while those of Bax protein experienced a huge increase $(P<0.01)$; and the expression levels of LC3-II, Beclin-1, Atg5, Atg7, Atg12 and Bcl-2 proteins in baicalin-treated groups witnessed a huge decrease $(P<0.05$ or $P<0.01)$, while Bax proteins were significantly increased in a dose-dependent manner $(P<0.05$ or $P<0.01)$ ( Figs 4 and 5).

\section{Conclusion}

The results of joint pathological tissue, foot swelling and arthritis index could be seen in this experiment, after administration of baicalin, inflammatory cell infiltration and synovial hyperplasia was alleviated, foot swelling and arthritis index witnessed a huge decrease, which illustrates the fact that baicalin has strong anti-inflammatory and anti-rheumatoid activities. These years, it has been reported that baicalin's anti-inflammatory mechanism might be related to its regulation of autophagy.

Autophagy is the transport of damaged or obsolete organelles and proteins to lysosomes for the decomposition of proteins under the stress of endoplasmic reticulum (ER), hypoxia, starvation, heat shock and microbial infection to maintain intracellular balance [17]. Autophagy protects cells from the damage caused by viruses or bacteria, and regulates apoptosis, immune response and inflammation [18]. Beclin-1 is a homologue of yeast Atg 6 and a key gene to initiate autophagy [19]. Once the beclin-1 gene is activated, Atg7 initiates Atg5-Atg12 binding and LC3-I lipid reaction to form LC3-II [20,21], marking the occurrence of autophagy. LC3-II is a marker of autophagy and is widely used to monitor the autophagic activities of cells. Therefore, Beclin1 and LC3 play an essential role in autophagy.

Studies have shown that autophagy can also reduce inflammatory responses through apoptosis, there is a complex interaction between autophagy and apoptosis, and the inhibition of autophagy can induce the apoptosis of various cancer cells [22]. Kato et al. [23] have found that the activation of autophagy can restrict the endoplasmic reticulum of fibroblasts to protect cells from apoptosis, which can promote the massive proliferation of rheumatoid arthritis fibroblast-like synoviocytes (RA-FLS) to increase the release of inflammatory factors, leading to the exacerbation of the inflammatory reaction in arthritis. 
Recent studies have indicated that autophagy is participate in the pathogenesis of RA by modulating synovial fibroblasts, immune cells, and pro-inflammatory cytokines, etc. [24]. At the same time, autophagy and immune cells coordinate with each other to adjust the emancipate of inflammatory cytokines such as, tumor necrosis factor (TNF), interleukin (IL), cyclo-oxygen-ase (COX), etc. RA-FLS and inflammatory cells can secrete a large number of cytokines, such as TNF-, IL-17, IL-6 and IL-1, and are participated in the occurrence and development of diseases [25]. COX-2 is an important prostaglandin synthase in inflammations, and can be stimulated by inflammatory cytokines or bacterial lipopolysaccharides to be highly expressed in RA-FLS and inflammatory cells [26], suggesting that RA-FLS and inflammatory cells can promote the expression of inflammatory cytokines by activating autophagy [20].

The Western blot detection of expression levels of autophagic proteins Beclin-1, Atg5, Atg7, Atg12 as well as LC3-II proteins was used for the monitoring of the autophagic level of tissues dynamically in this study. Compared with those in the normal group, the expression levels of autophagic proteins Atg5, Atg7, Atg12, Beclin-1 and LC3-II increased in the synovial tissue of rats in the model group, indicating that there was the activation of autophagy in the joint tissue of adjuvant arthritis rats; the expression levels of autophagic proteins decreased after the intervention with baicalin, showing that baicalin could inhibit the autophagy of synovial tissue in adjuvant arthritis rats.

Moreover, the inhibition of autophagy is related to the increase of apoptosis [26]. Increased apoptosis, reduces inflammation. Autophagy participates in both the induction and inhibition of inflammations. The activation of autophagy contributes to the secretion of inflammatory cytokines such as TNF- $\alpha$ and IL-6 [27]. Therefore, baicalin was administered intragastrically to rats with adjuvant arthritis. According to the result, it is illustrated that the expression levels of autophagy-related proteins, anti-apoptotic factor Bcl-2 protein and inflammatory factors (IL-1, IL-6, IL-17, TNF- $\alpha$ and CX-2) increased significantly, while those of pro-apoptotic factor Bax protein decreased in the model group; after the intervention with baicalin, the expression levels of anti-apoptotic factor Bcl-2 protein and inflammatory factors decreased, while those of pro-apoptotic factor Bax protein increased, suggesting that baicalin may play an anti-inflammatory effect by restraining autophagy and inducing apoptosis.

\section{Acknowledgments}

This research was supported by the Science and Technology Department of Jilin Province Science and Technology Research Project [grant number: 20190304048YY], Jilin, China; Jilin Province Health Science and technology capacity improvement project [grant number: 2019J046], Jilin, China; Science and Technology Plan Project of Jilin City [grant number: 201820847], Jilin, China; Jilin Province Health Science and Technology Capacity Improvement Project [grant number: 2021JC085], Jilin, China.

\section{Conflict of interest}

None to report.

\section{References}

[1] Manganelli V, Recalchi S, Capozzi A, Riitano G, Mattei V, Longo A, et al. Autophagy induces protein carbamylation in fibroblast-like synoviocytes from patients with rheumatoid arthritis. Rheumatology. 2018; 57: 2032-2041. 
[2] AKemble S, Croft AP. Critical role of synovial tissue-resident macrophage and fibroblast subsets in the persistence of joint inflammation. Front Immunol. 2021; 12: 715894.

[3] Jensen R, Christensen AF, Hartlev LB, Thomsen JS, Boel L, Laursen M, et al. Calcified cartilage differs in patients with end-stage primary osteoarthritis and secondary osteoarthritis due to rheumatoid arthritis of the hip joint. Scand $\mathrm{J}$ Rheumatol. 2021; 13: 1-11.

[4] Feng FB, Qiu HY. Effects of Artesunate on chondrocyte proliferation, apoptosis and autophagy through the PI3K/AKT/mTOR signaling pathway in rat models with rheumatoid arthritis. Biomed Pharmacother. 2018; 102: 12091220.

[5] Svensson MND, Zoccheddu M, Yang S, Nygaard G, Secchi C, Doody KM, et al. Synoviocyte-targeted therapy synergizes with TNF inhibition in arthritis reversal. Sci Adv. 2020; 6(26): eaba4353.

[6] Xu J, Liu JL, Yue GL, Sun MQ, Li JL, Xiu X, et al. Therapeutic effect of the natural compounds baicalein and baicalin on autoimmune diseases. Mol Med Rep. 2018; 18: 1149-1154.

[7] Zhang X, Qin Y, Ruan W, Wan X, lv C, He L, et al. Targeting inflammation-associated AMPK/Mfn-2/MAPKs signaling pathways by baicalein exerts anti-atherosclerotic. Phytotherapy Research. 2021 ; 35(8): 4442-4455.

[8] Dziadek K, Kopeć A, Czaplicki S. The petioles and leaves of sweet cherry (Prunus avium L.) as a potential source of natural bioactive compounds. Eur. Food Res Technol. 2018; 244: 1415-1426.

[9] Zhang X, Zhao Q, Ci X, Chen S, Chen L, Lian J, et al. Effect of baicalin on Bacterial Secondary Infection and Inflammation Caused by H9N2 AIV Infection in Chickens. Biomed Res Int. 2020; 2020: 2524314.

[10] Fang J, Zhu YH, Wang HD, Cao BL, Fei MX, Niu WH, et al. Baicalin protects mice brain from apoptosis in traumatic brain injury model through activation of autophagy. Front Neurosci. 2019; 12: 1006.

[11] Bai H, Yuan R, Zhang Z, Liu L, Wang X, Song X, et al. Intra-articular Injection of Baicalein Inhibits Cartilage Catabolism and NLRP3 Inflammasome Signaling in a Posttraumatic OA Model. Oxid Med Cell Longev. 2021; 2021: 6116890.

[12] Cai Z, Lin Y, Chen Y. Baicalin inhibits BLyS-mediated Th17 cell differentiation and inflammatory response in collageninduced arthritis mice. Chinese Journal of Pathophysiology. 2020; 36(7): 1294-1301.

[13] Zhu L, Wang H, Wu Y, He Z, Qin Y, Shen Q. The autophagy level is increased in the synovial tissues of patients with active rheumatoid arthritis and is correlated with disease severity. Mediators Inflamm. 2017; 2017: 7623145.

[14] Li Z, Wang HZ, Yu W. The Autophagy Level Is Increased in the Synovial Tissues of Patients with Active Rheumatoid Arthritis and Is Correlated with Disease Severity. Mediators Inflamm. 2017; 2017: 1-9.

[15] Kim EK, Kwon JE, Lee SY, Lee EJ, Kim DS, Moon SJ, et al. IL-17-mediated mitochondrial dysfunction impairs apoptosis in rheumatoid arthritis synovial fibroblasts through activation of autophagy. Cell Death Dis. 2017; 8(1): e2565.

[16] Yoo SA, You SY, Yoon HJ, Kim DH, Kim HS, Lee K, et al. A novel pathogenic role of the ER chaperone GRP78/BiP in rheumatoid arthritis. J Exp Med. 2012; 209: 871-86.

[17] Tong WW, Zhang C, Hong T, Liu DH, Wang C, Li J, et al. Silibinin alleviates inflammation and induces apoptosis in human rheumatoid arthritis fibroblast-like synoviocytes and has a therapeutic effect on arthritis in rats. Sci Rep. 2018; $8(1): 3241$.

[18] Wang H, Zheng Y, Huang J, Li J. Mitophagy in antiviral immunity. Frontiers in Cell and Developmental Biology. 2021; 9: 723108.

[19] Tang J, Lu XJ, Chen FF. Effects of perfluorooctanoic acid the associated genes expression autophagy signaling pathway of carassius auratus lymphocytes in vitro. Front Physiol. 2018; 12: 1-11.

[20] Peeters JGC, Graeff ND, Lotz M, Albani S, Roock SD, Loosdregt JV. Increased autophagy contributes to the inflammatory phenotype of juvenile idiopathic arthritis synovial fluid T cells. Rheumatology. 2017; 56: 1694-1699.

[21] Gunadi JW, Tarawan VM, Setiawan I, Lesmana R, Wahyudianingsih R, Supratman U. Cardiac hypertrophy is stimulated by altered training intensity and correlates with autophagy modulation in male Wistar rats. BMC Sports Sci Med Rehabil. 2019; 11: 9 .

[22] Abdullah, Mashan L. Al-Shabanah, Othman Hassan, Zeinab K. Hafez, Mohamed M. Eugenol-Induced Autophagy and Apoptosis in Breast Cancer Cells via PI3K/AKT/FOXO3a Pathway Inhibition. International Journal of Molecular Sciences. 2021; 22: 1422-0067.

[23] Kato M, Ospelt C, Kolling C, Shimizu T, Kono M, Yasuda S, et al. AAA-ATPase p97 suppresses apoptotic and autophagyassociated cell death in rheumatoid arthritis synovial fibroblasts. Oncotarget. 2016; 7(39): 64221-64232.

[24] An QY, Yan WK, Zhao Y, Yu KQ. Enhanced neutrophil autophagy and increased concentrations of IL-6, IL-8, IL-10 and MCP-1 in rheumatoid arthritis. International Immunopharmacology. 2018; 65: 119-128.

[25] Sun F, Gu WJ. Baicalin attenuates collagen-induced arthritis via inhibition of JAK2-STAT3 signaling and regulation of Th17 cells in mice. J Cell Commun Signal. 2019; 13: 65-73.

[26] Vomero M, Manganelli V, Barbati C, Colasanti T, Capozzi A, Finucci A, et al. Reduction of autophagy and increase in Apoptotic correlates with a favorable Clinical outcome in patients with Rheumatoid arthritis treated with anti-TNFDrugs. Arthritis Res Ther. 2019; 21: 1-11.

[27] Yang R, Zhang Y, Wang L, Hu J, Wen J, Xue L, et al. Increased autophagy in fibroblast-like synoviocytes leads to immune enhancement potential in rheumatoid arthritis. Oncotarget. 2017; 8: 15420-15430. 